This bieg is
nowindered
in scopus

\title{
THE RELATIONSHIP BETWEEN VARIATIONS OF GRID LAYOUT AND BURGLARY
}

\author{
Saniah Ahmad Zaki' \& Jamalunlaili Abdullah ${ }^{2}$ \\ ${ }^{1 / 2}$ Faculty of Arciritecture, Planning of Sumeying \\ UNIVERSITI TEKNOLOGI MARA, SHAH ALAM, MALAYSIA
}

\begin{abstract}
The study examined the relationship betwoen urban spaces and burglary in Malaysian grid-like residential layouts located in a local authority area in the Klang Valley. It analysed first, the degree of grid in the layouts to understand how they could influence burglary rate, and, second, the spatial patterns of burglary in those layouts. The instrument used in this reseatch was space syntax, a tool that analyse urban spaces. By comparing burglary rates to syntaclical spatial antributes in six residential layouts, the findings showed how spatial attributes influenced burglary. It also attempted to relate how degree of permeability of grid-like layouts may have affected vulnerability. It concluded by suggesting for further studies in other residential layouts in this coantry.
\end{abstract}

Keywords: burglary, grid-like layout, space syntax, permeability

\section{INTRODUCTION}

Discussions on the relationship between environment and crime; and the spatial patterning of crime started way back in 1920 s with the work by Shaw and McKay at the Chicago School when they found that juvenile delinquency is related to environment where they lived rather than to a particular group of people. Subsequently, Brantingham and Brantingham in 1975 investigated the spatial distribution of crime using urban form models they constrocted which they geocoded burglaries to city blocks in locations burglary occurred, as well as mapping burglary rates. They identified locations in the neighbourtioods that are safe and those that may be vulnerable to burglary. Later, Brantingham and Brantingham and Beavon et al. (1994) suggested that criminals select targets

\footnotetext{
${ }^{4}$ Associate Professor. Email saniahzaki(a) salam.uitm.edu.my

A Associate Professor. Email- jamal858@salam.uitm.edumy
} 
based on their routine paths, which apparently are the highly accessible strcets that are actively used by people. Beavon et al. also implied there are certain locations in which crime is likely to be concentrated.

Two other influential works were that of J. Jacobs (1961) and $O$, Newman (1972). Both identified characteristics of streets that are at risk to crime and streets that are safer, but with conflicting explanations. But, in a more recent study by Hillier and Shu $(2000)$ using space syntax, they not only showed that crime is influenced by environment (spaces in residential areas) they also indicated the features in urban layouts that affected the uneven distribution of burglary. They found that the degree of integration of spaces in the layouts seems to correspond to the type of layout; the traditional layout has more integrated spaces, while the more broken-up layout has less integrated spaces. The traditional grid-iron layout was reported to start way back in the fifth century BC when Hippodamus drew up Miletus City plan thought to be the most practical urban planning scheme. Since then, grid-iron bocame a regular feature in the planned cities of the Greeks as well as the Romans and in Spain.

Various forms of grids from the rectangular block, the parallel grids and others were also repurted to be introduced in cities way back in the 1900 . Although these forms mainly contain linear and continuous street type, and allow through movement, they differ in length. In some, the streets are longer, more continuous and less breaks, in others they are shorter and as such more breaks. Later, when other forms of street pattern example cul-de-sacs and loops were introduced, residential layouts appear to have lesser continuous, linear and through streets. The difference in forms between the earlier and later layouts is its degree of permeability. In the former, the layout is more permeable and it encouraged through movement; whereas in the Jatter, it is less permeable or impermeable, and restricts through movement. Street pattern not only seems to determine the shape and type of an area particularly residential layout, but most importantly the movements within a layout.

Although there have been studies that investigated how far these street pattems influenced movement of people, there are others who looked at a broader dimension, the environment, and how it relates to crime distribution as mentioned earlier. Some have also examined the relationship of the street patterns (or street layouts) and crime. It appears from a study by Shu $(2000)$ in a form of a PhD thesis that looked at the relationship between space and crime in various types of residential layouts, a safer layout would be one that have interconnected or integrated through streets, with dwellings facing out on to 
both sides of the streets. Shu implicated that grid-like layouts appeared to be safer compared to tree-like layout that consists mainly cul-de-sacs and are more broken-up. The question is: If grid-like layout appeared safer would different variations of grid layout (i.e. from puse grid to the impure grid) still work to reduce vulnerability to burglary?

A research investigated the distribution of burglary in a Malaysian township that comprises mainly grid-like residential layout. By using space syntax, this study extended the past study into how each aspects of design interacted to influence burglary distribution in various grid-like layouts.

\section{LITERATURE REVIEW}

The most influential work in looking at the relationship between street patterns and erime has been that of Jane Jacobs (196I), who identified the characteristics of streets that are more at risk to crime and streets that are safer. Jacobs observed that streets in which there were more activities and more people, strangers and residents, crime was lower. The design of these streets as observed by Jacobs are more of a traditional, street-based (grid layout), in which the strangers (passers-by) acted as casual surveillance. She also noted the orientation of buildings along these streets was onto the streets. According to Jacobs, this allowed the owners of the buildings to set their 'eyes on the street'. By having the entrance of buildings onto streets, it indicated the importance of generating intervisibility amongst buildings aiong the streets. Whereas in parts where there were fewer people and lesser activities, such as those with a morc suburban characteristic, she observed that crime was higher.

Contradictory to Jacobs is the work by Oscar Newman (1972) who also attempted to show the relationship between crime and environment but with conflicting explanations. Newman believed that in a neighbourhood where the streets are controlled and owned by residents, there is virtually very little crime. $\mathrm{He}$ also explained that because the streets are private, any strangers are considered as intruders and are as such they are to be under constant surveillance. Hillier and Sahbaz (2008) also reported that Newman finds too many people in spaces create anonymity and allows criminals to access their victims, which will weaken the possibility of residents to control their own environment. A more recent study by Hillier and Shu (2000) using space syntax, not only showed that crime is influenced by environment (spaces in residential areas) they also indicated the features in urban layouts that affected the uneven distribution of burglary. They looked at how different types of layouts and 
streets have influenced burglary rate. They found that the degree of integration of spaces in the layouts seems to correspond to the type of layout; the traditional layout has more integrated spaces, while the more broken-up layout has less integrated spaces. These findings seem to agree with Jacobs' observation.

Hillier and Shu's study concluded with three main points: first, crime tends to seek the most vulnerable type of space within an area. Second, for an area to be safe, it depends on the co-presence of a group of factors, which are the positioning in the overall layout and the immediate surroundings of the dwelling. Finally, there are factors which can reduce crime in a layout but can increase it if other factors are present (Hillier and Shu, 2000). Having established the conclusions, they deduced that a safer layout would be one that have interconnected or integrated through streets, with dwellings facing out on to both sides of the streets.

\section{RESEARCH METHODOLOGY}

The question: would different variations of grid layout (i.e. from pure grid to the impure grid) still work to reduce vulnerability to burglary. To answer this question, a study was conducted which investigated the spatial distribution of burglary in grid-like layouts at two-levels: the area and the street. The first level examined why there were variations in the spatial distribution of burglary between grid-like residential layouts. The second level was at a finer scale, which were the street segments; individual dwelling and its immediate environments. At this second level analysis, the local factors that influence dwellings vulnerability were investigated. Nonetheless, in this paper only the findings of the fitst level analyses are presented.

Six residential areas were selected randonly within a Local Authority area located in the Petaling District of Selangor. These areas are of varying degrees of grid layouts, from the pure grid with mainly linear through streets to the impure grids with some cul-de-sacs. An inventory questionnaire used consisted of five sections was designed to address the question. The first section contains five questions capturing the house protile such as type of house, type of door, location of house entrance, location of house in a row, and number of sides of house exposed on to the space. The second section determining the availability of situational factors such as alarm outside the property, the presence of CCTV, occupancy of the house, grills on doors, grills on windows, and form of deterrents (e.g. dogs or membership of neighbourhood watch). The 
third section, explores the visibility of house front, which includes the quality of visibility of the house front measured using a 5-point Likert scale from 1 -very poor to $5=$ excellent. The assessment as to the degree of visibility of house front was further established by identifying availability of features that conceal the front, the form of features, fencing material, and fencing height. The fourth and final sections look at the side and back of the burgled house respectively. Each of the sections determines how the side and back of the house is exposed. its accessibility from the side and back lanes, as well as the availability and forms of climbing elements that could have provided easy entry to burglars.

A total of 1228 houses were recorded of which $380(31 \%)$ were burgled houses and $848(69 \%)$, non-burgled houses. The burgled houses were based on Police records between the years 2006 to 2008 . Non-burgled houses situated on both sides of the burgled houses (and in some cases opposite of the burgled houses) were also selected for the inventory. The purpose was to compare and examined why some houses are more vulnerable and others safer. However, the comparison between burgled and non-burgled houses is not discussed in this paper. The study used space syntax as a tool that allows spaces in the grid-like layouts to be analysed quantitatively and compared with other quantitative variables. GIS (geographical information system) was also used to provide the database for spatial data and also to map the precise location of burglaries. Based on this map, the spatial concentration of burglaries was examined in relation to the streets in the areas. A simple statistics, regression plots and ANOVA were used to explore the relationship between burglary rate and spatial factors and syntactical variables using Statview statistical software.

Space syntax is a set of techniques for representing and analysing street networks of cities in such a way as to bring to light underlying patterns and structures which influence patterns of activity in space, most notably movement and land use (Hillier and Sahbaz, 2008). Before the case study areas could be analysed, an axial map (a space syntax line map) was first produced. The axial map of the six case study areas (Appendix 1), in which the streets or spaces (represented as lines) in an area, were drawn and then processed in a space syntax software (example Axman). Axial maps when processed will produce coloured lines from the warmer colours (red) through the cooler colours (blue). These coloured lines indicatc the integration level of spaces based on its movement potentials. A red coloured line indicates that it is the most integrated space and a blue line, the least integrated. The global integration level (represented as radius $n$ ), measures each line in relation to the whole system, and the local integration level (represented as radius 3), measures the complexity of lines up to three steps away from the line. Besides the integration 
levels of spaces, other syntactical variables can also obtained. These include: connectivity, intelligibility, and synergy. Connectivity refers to the degree of connections of each line to another; intelligibility is the relationship between the global integration and connectivity that shows how well residents and visitors are able to understand in moving in and out of an area, and synergy of a layout (local-to-global), is the measure of co-presence between residents and strangers in the area. Burglary data of throe years $(2006-2008)$ provided by the Malaysian Royal Police Force (PDRM), was mapped as dots onto axial map. But, in complying with the confidentiality of the burglary data, the study areas have been anonymised and named as Areas 1, 2, 3, 4,5, and 6 .

\section{THE CASE STUDY AREAS}

The cuse study areas are located within a local authority area in the Klang Valley. These areas, which are socio-economically homogenous, are all laid out in different variations of grid, that is from the more pure grid to the lesser pure or impure grid. The inherent features of the layouts are that they generally constitute through, linear streets and in some areas with very few cul-de-sacs. Houses that are mainly terraced tend to line up the streets with front of the houses facing onto the local roads and the back onto back lanes.

The roads are arranged hierarchically, linking the local roads to the main road. Although this arrangement may be common in Malaysian residential layouts, in some, the hicrarchical layout are more prominent than others. Areas 5 and 6 are examples of areas with such layout compared to the other areas. These varied hierarchies relates to permeability of the layouts. Areas with more direct access to the main roads tend to be more permeable than those that have less direct access and are also more hierarchical.

In considering these features, the areas are indexed based on a 4-point scale as follows: 
PLANVING MALAYSIA

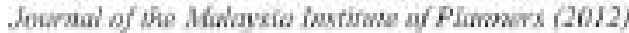

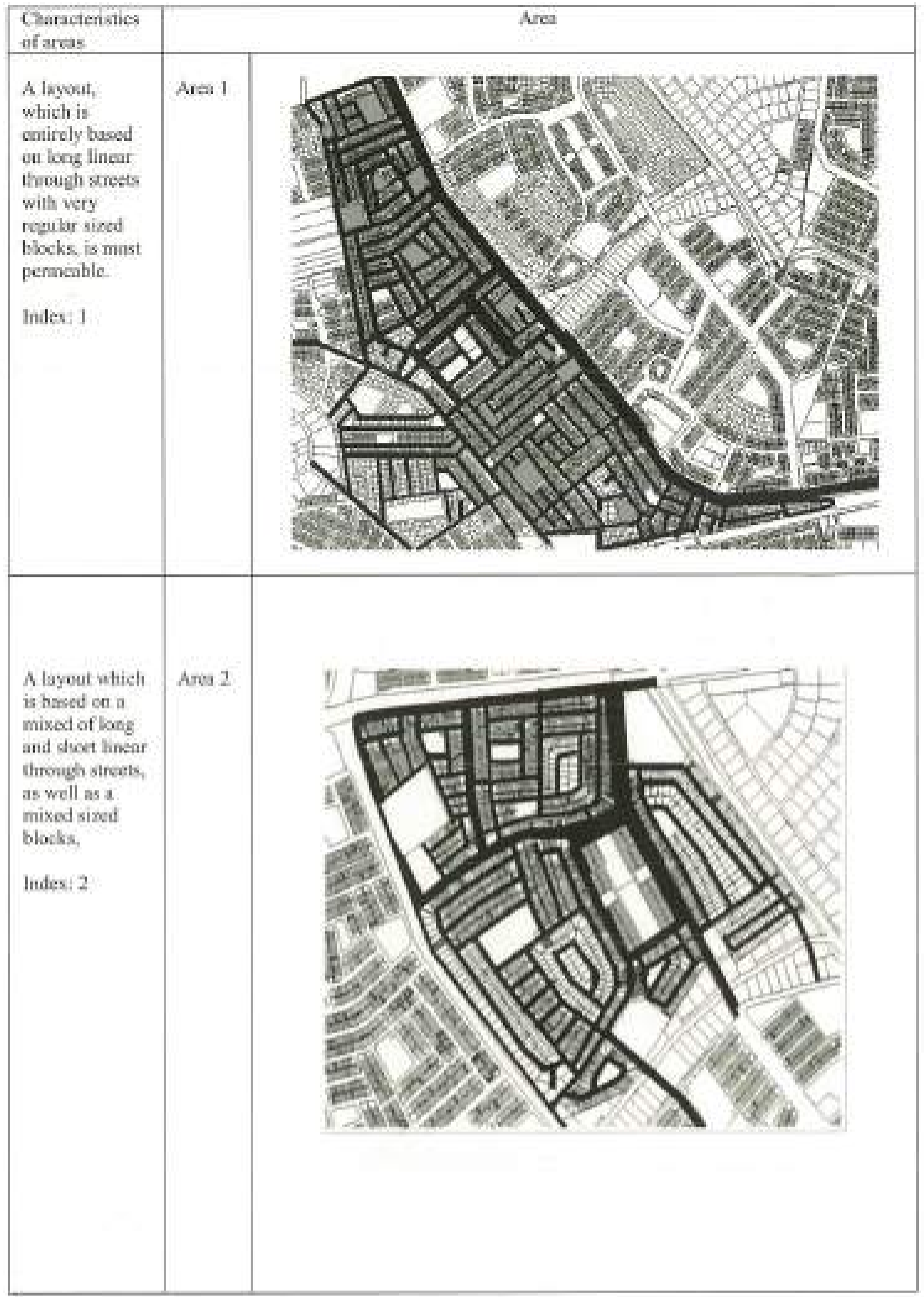




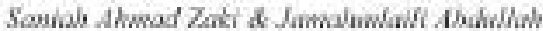

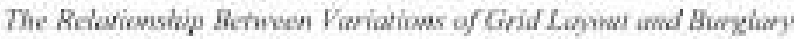

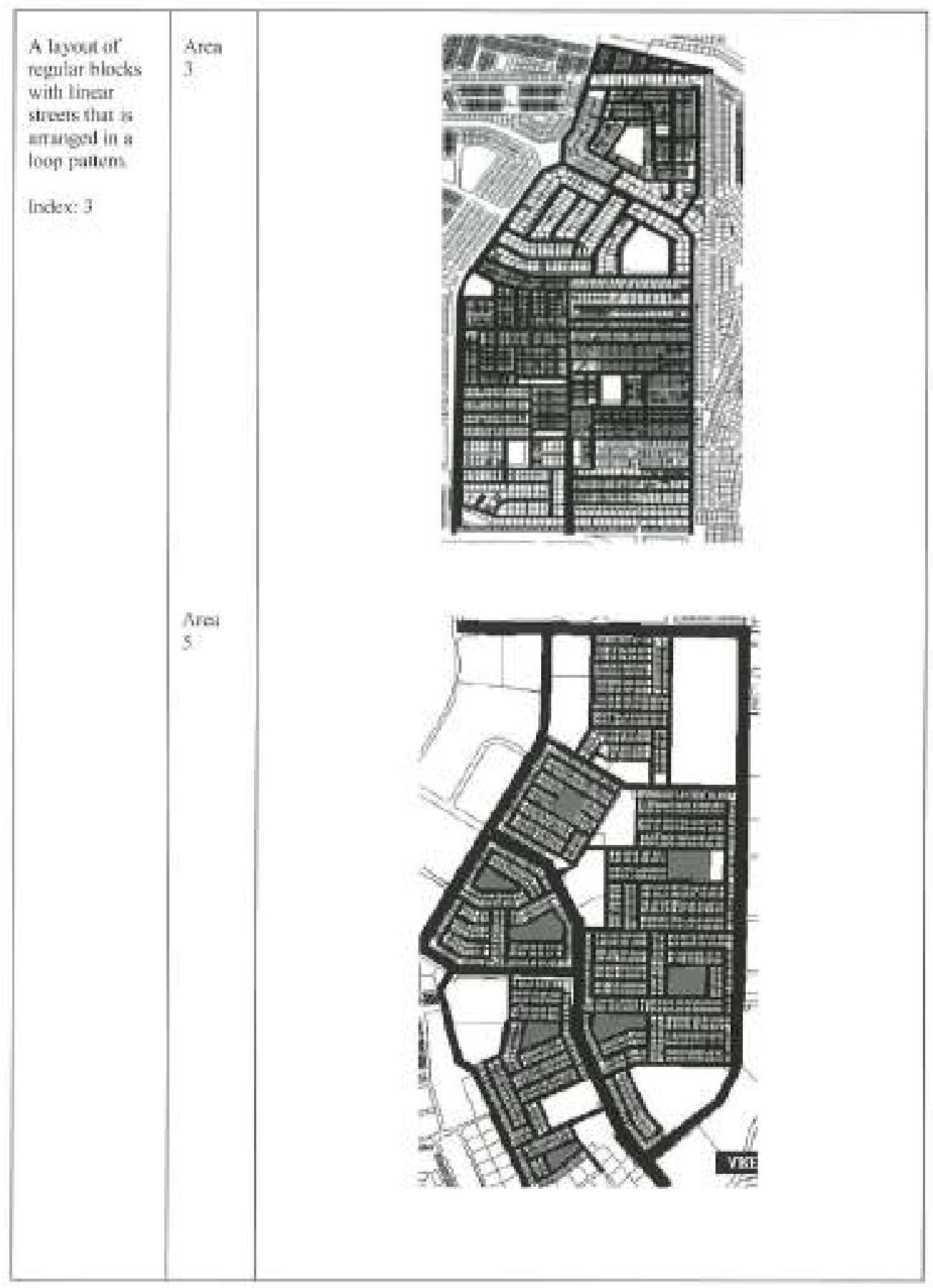




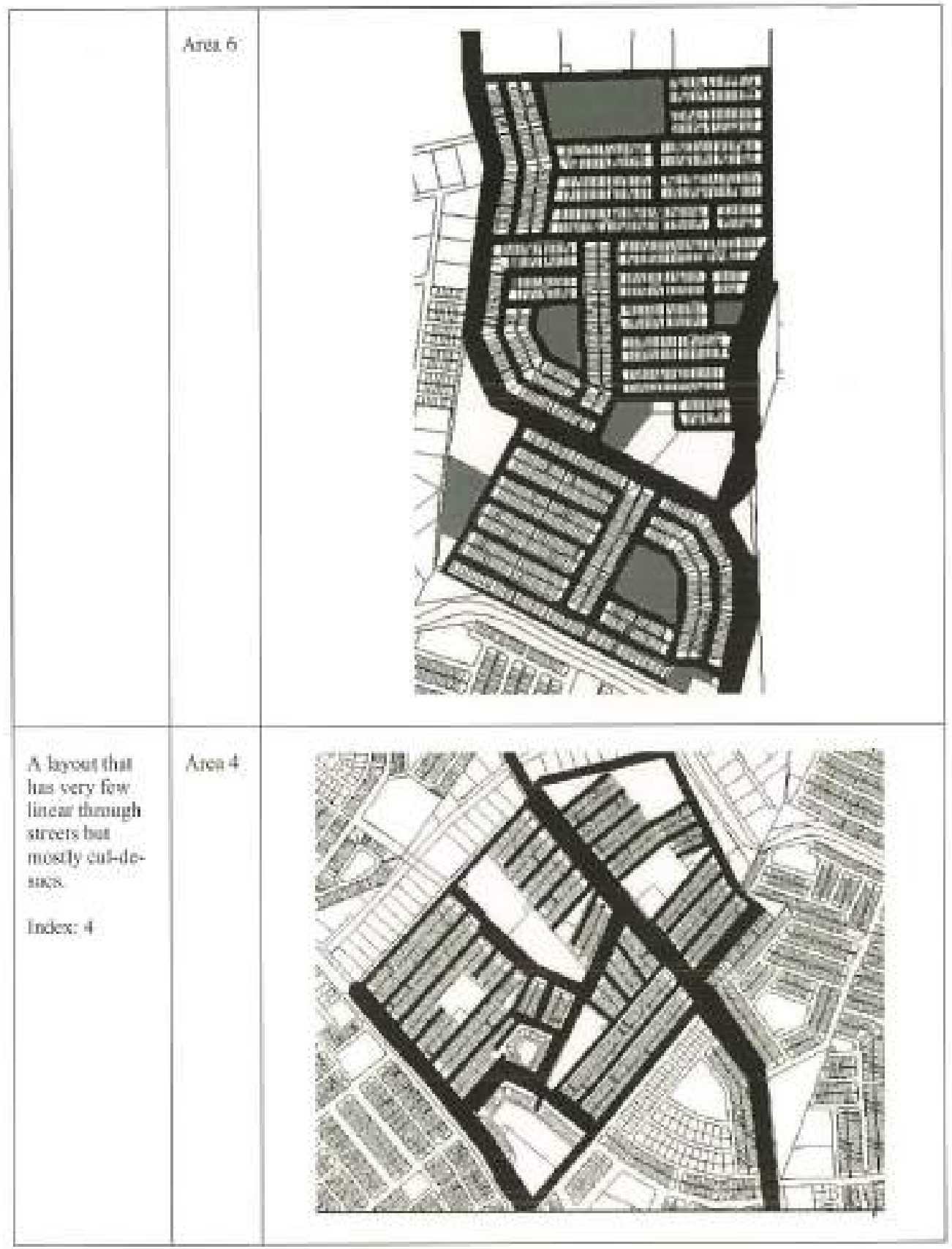




\section{FINDINGS}

\section{i. At the area level}

\section{a. Relationship between characteristics of areas and burglary rate}

At this level the variations in the spatial distribution of burglary in residential ureas was first examined. This was done by comparing the relationship of burglary rate with spatial characteristics between areas. For this purpose burglary rate was calculated based on the number of burglary per one thousand (1000) houses. A data table of six case study areas was constructed, that include spatial pattern type, degree of connectivity, total number of houses, breakdown of house type, permeability index, and three-year period burglary datu (Table 1).

The table shows that out of the six areas, three (Areas 1, 2 and 3) have more than 20 burglaries per 1000 houses and the other three (Areas 4,5 and 6 ) have less than 20 barglaries per 1000 houses. Why are some areas safer with lower burglary rate but others higher? Although, it may initially appear that areas with spatial characteristics indexed on a scale of 1 and 2 (from very regular layout to less regular) has higher burglary rate, Area 3 that is indexed on a scale of 3 has also high burglary rate. Ironically, Areas 5 and 6 which are also spatially indexed on the seale of 3, have lower burglary rates. Similarly, the degree of grid when visually analysed does not appear to be related to burglary rate. Among three areas indexed as 4 (purtially impure grid). Area 3 has high burglary rate, whereas the other two areas (Areas 4 and 6), lower rate. In a regression analysis, it is shown that the degree of grid is moderately related to burglary rate (Figure D) with an r-squared of 0.451 . Nonetheless the p-value in the ANOVA table indicates that the relationship is weakly significant. 


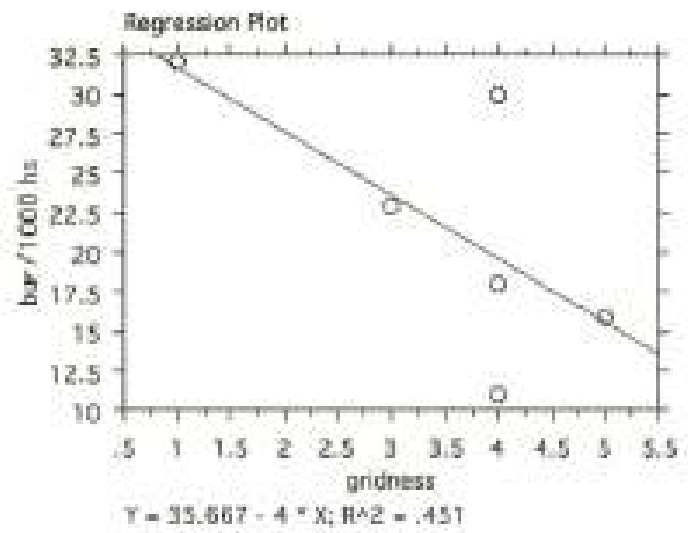

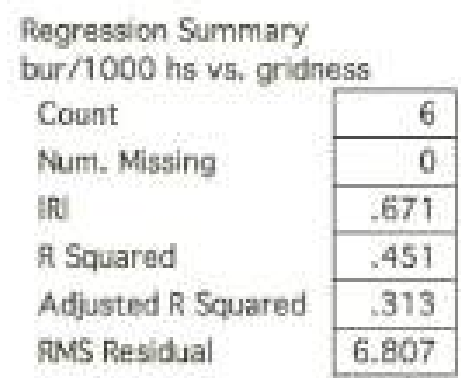

ANDVA Table

bur/1000 hs vs. gridness

\begin{tabular}{l|r|r|r|r|r|} 
& \multicolumn{2}{c}{ DF Sum of Squares } & \multicolumn{1}{c}{ Mean Square } & \multicolumn{1}{c|}{ F-Value } & p-Value \\
Regression & 1 & 152.000 & 152.000 & 3.281 & .1443 \\
\cline { 2 - 7 } Residual & 4 & 185.333 & 46.333 & & \\
Total & 5 & 337.333 & & & \\
\cline { 2 - 7 }
\end{tabular}

Regression Coethcients bur/1000 hs vs. gridness

\begin{tabular}{|c|c|c|c|c|c|}
\hline & Coefhcient & Std. Error & Std. Coeff, & t-Value & P-Value \\
\hline intercept & 35.667 & 8.214 & 35.667 & 4,342 & .0122 \\
\hline gridness & -4.000 & 2.208 & .671 & -1.811 & .1443 \\
\hline
\end{tabular}

Figsere I: Redabionship hetween barglary rate and degree of gridness 
When the type of houses in the areas was next eompared to burglary rates, it appears to indicate that areas constituting of only terraced houses $(100 \%)$ have lower burglary rates compared to those with mixed type of houses example in Areas 1, 2 and 3, where there are mixed of terraced and detached houses. The study then attempted to find if permeability index is calculated, which is the sum between the spatial pattern and scale of grid, could it be related to burglary rate. Hillier and Shu (2000) have suggested that the more open and permeable layout with through streets that facilitate continuous pedestrian and vehicle movements are less at risk to burglary than a layout which is more broken-up, closed and impermeable. Looking at the table it seems to implicate that only two areas (Areas 1 and 2) that have higher degree of permeability also have high burglary rate; and areas with lower degree of permeability lower burglary rate (Areas 4 and 5). However, in two other areas (Areas 3 and 6) their permeability indices do not seem to relate to burglary rate. It looks as if permeability of the case study areas (Malaysian residential layouts) affects burglary differently from that in a Westem country.

Thus, it secms to suggest that at the area level, only housing type appears related to burglary tate. Areas appeared to be safer if the housing type is homogenous. In a study by Bowers, Johnson and Pease (2005), they found that areas with homogenous housing are less targeted by burglars compared to areas with heterogeneous bousing. They further noted that terraced houses with two sides exposed (front and back of house) are less at risk compared to detached houses that have more windows and doors (more sides exposed). These findings seems consistent with the findings in a study by Hillier and Shu (2000), in which they described the terraced houses as having less exposure (at least two sides) onto the spaces provides less opportunity to burglars compared to detached houses that bave four sides exposed allowing more opportunities to burglars to enter a property.

However, when regression analysis was performed, the result suggests a weak relationship between terraced houses and burghary rate with p-value that indicates weakly significant. As pointed by Hillier and Shu (2000), the copresence of a group of factors would determine the safety of an area, which would prove difficult at the area level. 
Table I: The data tuble belons illesirates a semmary of the characteristics of the six case siudy areas

\begin{tabular}{|c|c|c|c|c|c|c|c|c|}
\hline \multirow[t]{2}{*}{ Ants } & \multirow{2}{*}{$\begin{array}{l}\text { Spatial } \\
\text { Patticm }\end{array}$} & \multirow{2}{*}{$\begin{array}{l}\text { Scale of } \\
\text { grikthese }\end{array}$} & \multirow{2}{*}{$\begin{array}{c}\text { Total nox of } \\
\text { houses }\end{array}$} & \multicolumn{2}{|c|}{ Fonse Type } & \multirow{2}{*}{$\begin{array}{l}\text { Spatial - } \\
\text { Cindincss }\end{array}$} & \multirow[t]{2}{*}{ Birt } & \multirow[t]{2}{*}{ Bur Rate } \\
\hline & & & & Terrsue & Dotsch & & & \\
\hline 1 & 1 & 1 & 4439 & $4035(90.9 \%)$ & $40419.10 \%)$ & 2 & 142 & 32 \\
\hline 2 & 2 & 3 & 2728 & $1139(41.75 \%)$ & $1589(58,25 \%)$ & 5 & 64 & 23 \\
\hline 3 & 3 & 4 & 2003 & $1047(79.07 \%)$ & $436[20.935 \%$ & 7 & 62 & 30 \\
\hline 4 & 4 & 4 & 1442 & $1442(100 \%)$ & $=$ & 8 & 26 & 18 \\
\hline 5 & 3 & 5 & 4057 & $405 t(100 \%)$ & s & 8 & 68 & 16 \\
\hline 6 & 5 & 4 & 1581 & $1581.16056)$ & - & 7 & 18 & 11 \\
\hline
\end{tabular}

Note:

1. Arca: six areas that are socially homogenous, selected within one Local Authority area.

2. Spatial pattern: street layour indexed from 1 to 4 indicating degree of through roads in an area; pottem I for most regular with mainly linear through street over pallem 2 that are less regular with nixed through roads, to pattern 4 that are mainly cul-de-sacs

3. Scale of gridness: degree of grid is indexed based on the mean connectivity of areas; from 1 for very pure gnid theough to 5 for impure grid

4. Total housese: number of houses in each areas

5. House type: number and pereentage of each house type in each area: Terr (terraced); SD (demi-detached); Det (detached)

6. Spatial + gridness: sum of spatial type index and degree of grid with lowest value for highest degree of permeability and highest value for lowest degree of permeability

7. But; number of domestic burglary

8. Bur rate: number of burglary per 1000 houses based on three year period $(2006-2008)$ for each area

\section{b. Relationship between spatial syntactic properties and burglary rate}

The study next examined the relationship between burglary rate and spatial syntactic variables of the six grid-like luyouts. A visual analysis of these variables compared with the burglary rate appears to indicate that Area 1 is most vulnerable to burglary because: it is highly integrated to the whole system as well as to its surroundings; within the area its streets (or spaces) are also highly connected; and its high synergy value that suggests a high degree of copresence between residents and strangers in the area (Table 2). The less vulnerable areas (with lower burglary rates) appear to be less integrated both globally and locally; the streets are less connected, and, thus, lower synergy value. This pattem also can be visually analysed in the axial map (Appendix 2), in which, Area 1 has darker or warmer coloured lines compared to the other areas. Apparently, the most integrated line (darkest line) in the system borders 
north of Area 1. Similar dark colour lines border the sides (east and west) of this area.

Regression analyses were then performed to determine the significance of syntactic variables, and the strength of relationship between burglary rate and the syntactic variables. Nevertheless, the results of the analyses showed only radius $n$ (global integration) indicates a strong relationship with burglary rate with an $\mathrm{r}$-squared of 0.713 and a p-value of 0.0346 . The remaining syntactical variables were weakly related.

The graph (Fig, 2) shows that burglary rate is thigh in ureas in which the layout that is highly connected to the whole system. The more globally integrated an area, the more vulnerable it is to burglary.

Table 2: Burelary rate is six case study areas compared aginst spatial sy stuctie variables

\begin{tabular}{|c|c|c|c|c|c|c|}
\hline Aros & $\begin{array}{c}\text { Burg } 1000 \\
\text { huoses }\end{array}$ & $\begin{array}{l}\text { Kowhis in fglobad } \\
\text { micgralion! }\end{array}$ & $\begin{array}{l}\text { Rafius } 1 \text { (lowal } \\
\text { integration! }\end{array}$ & Com & Intell & Syourzy \\
\hline 1 & 32 & 0.83 & 2.58 & 4.77 & $a+3$ & 0.36 \\
\hline 2 & 25 & 0,77 & 2.27 & 401 & 0.47 & 0.21 \\
\hline 3 & 31 & $0, \mathrm{KN}$ & $18 x$ & 326 & 0.56 & 0,30 \\
\hline 4 & 18 & $0 . \mathrm{XO}_{0}$ & 2.11 & 337 & 057 & 0.13 \\
\hline 5 & 16 & 0,100 & 2.07 & 346 & 0.23 & 0.17 \\
\hline 6 & 11 & $0,6 f_{1}$ & 2,015 & 3.52 & 0.29 & 0.16 \\
\hline \multicolumn{7}{|c|}{$\begin{array}{l}\text { Note: } \\
\text { Conn- connectivity } \\
\text { Intell - intelligibilily }\end{array}$} \\
\hline
\end{tabular}




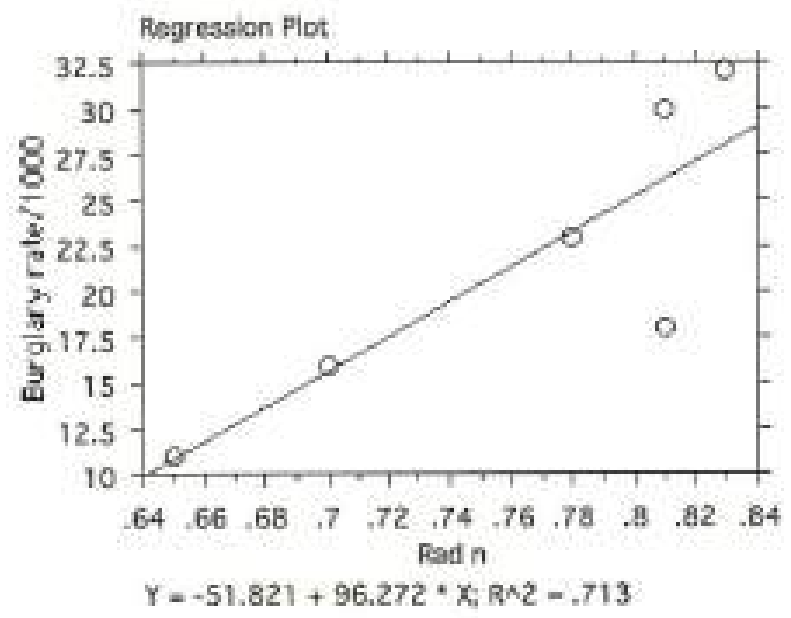

Regression Summary

Burglary rate/ 1000 vs. Rad n

\begin{tabular}{l|r|}
\cline { 2 - 2 } $\begin{array}{l}\text { Count } \\
\text { Num, Mssing }\end{array}$ & 6 \\
\cline { 2 - 2 } Ri & 0 \\
\hline R Squared & .844 \\
\hline Adjusted R Squared & .713 \\
\cline { 2 - 2 } RMS Residual & .641 \\
\cline { 2 - 2 } & 4.924 \\
\hline
\end{tabular}

\section{ANOVA Table}

Burgary rate/1000 vs. Rad n

\begin{tabular}{|c|c|c|c|c|c|}
\hline & DF & Sum of Squares & Moan Square & F-Value & P-Value \\
\hline Pegression & 1 & 240.360 & 240.360 & 9.915 & .0346 \\
\hline Residual & 4 & 96.973 & 24.243 & & \\
\hline Total & 5 & 337,333 & & & \\
\hline
\end{tabular}

\section{Regression Coefficients}

Burglary rate/ 1000 vs. Rad $n$

\begin{tabular}{l|r|r|r|r|r|} 
& \multicolumn{1}{c}{ Coeffcient } & \multicolumn{1}{c}{ Std. Error } & \multicolumn{1}{c}{ Std. Coeff, } & \multicolumn{1}{c}{ t-Value } & P-Vaue \\
\cline { 2 - 6 } Intercept & -51.821 & 23.425 & -51.821 & -2.212 & .0914 \\
\cline { 2 - 6 } Rad n & 96.272 & 30.575 & .844 & 3.149 & .0346 \\
\hline
\end{tabular}

Fieure 2: Relationship between berglary rate and radius n 


\section{c. Relationship between spatial categories and burglary rate}

The study also compared the spatial categories of the layouts with burglary rate, The properties considered were: 1) constitutedness of the streets, in which the number of entrance of houses that open to both sides of a street. A street is recorded as constituted if there are more than $70 \%$ of houses lining both sides of a street with their entrance open onto the street; 2) categories of space, which includes through carriageway, cul-de-sac driveway, and cul-de-sac carriageway; and also, intervisibility.

In a previous syntax-based study by Hillier and Shu, it has been shown that a layout is safer if its streets are generally constituted, with bigh intervisibility and mainly through carriageways. Unlike the previous study, the case study areas are grid-like layouts and as such the streets are mainly made-up of through carriageways. Nevertheless, the degree of constitutedness of streets varies. Area 5 has the least proportion of streets that are constituted $(46.2 \%)$ and Area 2, the most (more than $74 \%$ ). But, the proportion of constituted streets in grid-like layouts does not seem to relate to burglary rate, Perhaps, the high intervisibility of houses (low proportion of poor visibility in all areas) could have an influence in the burglary rate. This visual analysis was confirmed when the variables compared with burglary rate in regression analyses, showed weak relationship ( $\mathrm{p}$-value of more than 0.05 ). It has been shown that analyses at the area seale have partially explained the proportion of burglary rate between areas. With the exception of the global integration (radius $n$ ), all the other variables do not explain the uneven distribution of burglary between grid-like areas. Thus, it was essential for the study to examine at a much finer seale of the street level.

Table 3: Comparison betweon burglary rate per 1000 heuses and spatial cutegories

\begin{tabular}{|c|c|c|c|c|c|c|}
\hline \multirow{2}{*}{ Arca } & \multirow{2}{*}{$\begin{array}{l}\text { Aurglary nule pet } \\
\qquad 1000\end{array}$} & \multirow{2}{*}{$\%$ Coral } & \multicolumn{3}{|c|}{ Caicyovies of space } & \multirow{2}{*}{$\begin{array}{l}\text { To past } \\
\text { visibility }\end{array}$} \\
\hline & & & Wo thine & Ms culdri & $\%$ cule & \\
\hline 1 & 32 & 5910 & 39.41 & 0.00 & 1:5 & 21.8 \\
\hline 2 & 33 & 74.10 & 4x.311 & 1.511 & 6.2 & 20.4 \\
\hline 3 & 30 & 5260 & 99.40 & 0.31 & $a 2$ & 19.4 \\
\hline 4 & 18 & 06.80 & 85.70 & 6.00 & 141 & 6.0 \\
\hline 5 & 16. & 46.215 & I 11100 & 0.00 & po & 10.6 \\
\hline 6 & 11 & 70.20 & 07.20 & 200 & bo & 27.8 \\
\hline
\end{tabular}




\section{ii. At the street level}

It has been illustrated that burglary rate is unevenly distributed between areas. Although, at the area level it has been shown that the gridness or the degree of grid and permeability do not appear to be related to burglary rate, areas with homogenous housing (terraced houses only) have lower burglary rate than areas with beterogeneous housing. Nonetheless, if burglary is mapped (Appendix 2), it can also be seen that within each areas burglary is also unevenly distributed. Some spaces are more at risked than others. The question is why burglary is unevenly distributed within an area. In answering this question, a micro analysis at the street level was considered. At this level, the local factors that make dwellings vulnerable in areas were investigated. But for the purpose of this paper, the results presented are of $\mathrm{a}$ comparison of burglary rate at the street scale using band as the unit of analysis.

Unlike most models that look at cities based on function-first approach, space syntax is a form-function based approach. According to Hillier and Stonor (2010), the space syntax approach measures are configurational, in which the relationship of each space in a system to all others are calculated. Thus, the spatial element, which is the street segment between junctions, was suggested as the main form of syntactic analysis of a city. In a residential layout, the number of houses lining street segments may vary from as little as 1 unit of house to more than 50 units. Looking at that range of houses in the study areas, the study then divided the street segments into bands as follows:

Band 1:

$1-12$ houses

Band 2:

$13-24$ houses

Band 3:

Band 4:

Band 5:
$25-36$ houses

$37-48$ houses

more than 49 house

\section{a. Comparison between band and burglary rate}

At this level the study attempted to find which band has higher burglary rate or is less safe and which is safer. In comparing at the street scale, burglary was calculated in each band as per 12 houses, in which the number of burglary for each band was multiplied with 12 (houses) and the actual number of houses in each band as the denominator (Table 4). When bands in all the areas were compared visually to determine which is most vulnerable to burglary, the study found burglary rate tend to be highest in band 1 ( $1-12$ houses) in each of the areas with the exception for Area 1. A regression is performed to determine if the relationship between burglary and bands in the areas (except Area 1) is 
significant. The results showed that the relationship in five areas is statistically significant with r-squared of 0.492 and a p-value of $<0,0001$. Although it appears to implicate that houses in band 1 are at risk, Table 4 also showed that in 2 areas (Areas 1 and 6), burglary is also high in band 3 , in fact highest in band 3 for Area 1.

Why does the burgiary distribution pattern differ in Area 1? The study tested if burglary rate in this area is related with syntactic, spatial or local factors of the area. When burglary rate in its entire band was correlated with all the variables, it looks like there was a strong relationship with connectivity ( $r=$ 0.826 ). Similarly in a regression analysis the $\mathrm{r}$-squared was also strong with a value of 0.683 . But, in the ANOVA table, the p-value was 0.0847 , which is more than the significant value of 0.05 . All the other variables do not indicate any relationship with burglary rate in Area 1 .

Tahle A: Burglary rate per 12 houses in each band

\begin{tabular}{|c|c|c|c|c|c|c|c|c|c|c|c|c|}
\hline \multirow{2}{*}{ Band. } & \multicolumn{2}{|c|}{ Area 1} & \multicolumn{2}{|c|}{ Area 2} & \multicolumn{2}{|c|}{ Area 3} & \multicolumn{2}{|c|}{ Arta 4} & \multicolumn{2}{|c|}{ Arca 5} & \multicolumn{2}{|c|}{ Ares 6} \\
\hline & Burg. & Rate & Bent: & Rakc & Burg. & Rate & Birg. & Rate & Burg. & Kune & Bury. & Rate \\
\hline $1(1-12)$ & 39 & 1.78 & 13 & 1.95 & 20 & 1.68 & 2 & 267 & 22 & 1.64 & 2 & 109 \\
\hline $2(1.324)$ & 14 & 0.38 & 14 & 092 & 18 & 0.87 & 5 & 0.71 & 7 & 0.81 & 3 & 0.69 \\
\hline $3(23-36)$ & 31 & 2.211 & 14 & 0.63 & 10 & 0.60 & 6 & 0.38 & 7 & 0.40 & 3 & 1.09 \\
\hline $4(37-48)$ & $T$ & 0.75 & 16 & 0,45 & 3 & 0.30 & 2 & 0.27 & 3 & 045 & 3 & 0,43 \\
\hline $5(49->)$ & 51 & 0.59 & 7 & 15.24 & 9 & 0.38 & 11 & 6.26 & 25 & D.31 & 7 & 0.34 \\
\hline & 142 & & 64 & & 60 & & 26 & & $\phi_{1}$ & & 18 & \\
\hline
\end{tabular}




\begin{tabular}{|c|c|}
\hline \multicolumn{2}{|c|}{$\begin{array}{l}\text { Regression Summary } \\
\text { burglary rate por } 12 \text { vs. band }\end{array}$} \\
\hline Count & 30 \\
\hline Num, Msssing & 0 \\
\hline R & .701 \\
\hline R. Squared & .492 \\
\hline Adgusted R Squared & .474 \\
\hline RMS Residual & .474 \\
\hline
\end{tabular}

\section{ANOVA Table}

burgary rate per 12 vs. band

\begin{tabular}{|c|c|c|c|c|c|}
\hline & DF & Surn of Squares & Mean Square & f-Value & P-Value \\
\hline Regression & 1 & 6.087 & 6.087 & 27.111 & $<.0001$ \\
\hline Rlesidual & 28 & 6.286 & 225 & & \\
\hline Total & 29 & 12.373 & & & \\
\hline
\end{tabular}

\section{Regression Coethcients}

burglary rate per $12 \mathrm{va}$. band

\begin{tabular}{|c|c|c|c|c|c|}
\hline \multirow{3}{*}{$\begin{array}{l}\text { Intercept } \\
\text { band }\end{array}$} & Coettcient & Std. Error & Srd. Coeff, & tovalue & P. Value \\
\hline & 1.800 & .203 & 1.800 & 8.873 & $<0001$ \\
\hline & -.318 & .051 & -.701 & -5.207 & $<0001$ \\
\hline
\end{tabular}

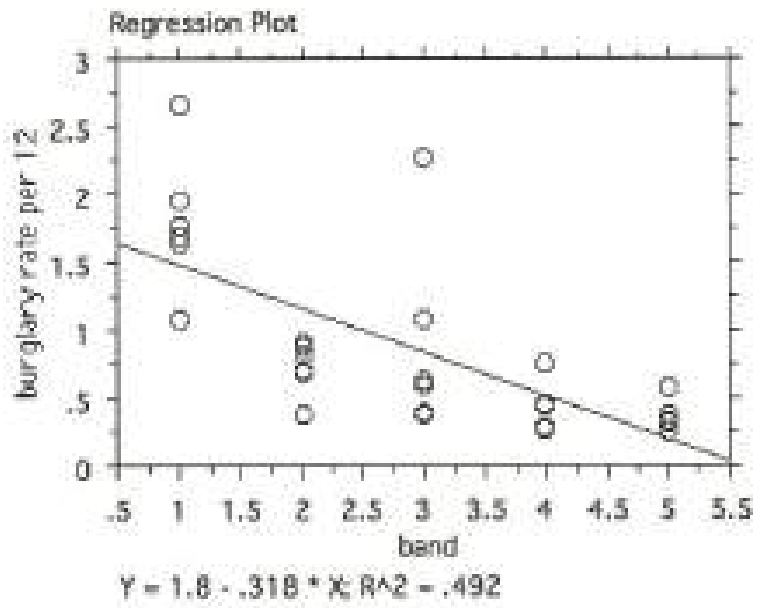

Flgere 3: Reladonship between burglary rate and band 


\section{CONCLUSION}

Grid-like layout has been a common street layout in residential areas throughout this country. Although a previous study by Hillier and Shu (2000) has suggested that grid-like layout is generally safer compared to tree-like layout, their study has also indicated that there are spaces in the former layout that is vulnerable to burglary.

Following Hillier and Shu's study, this study has attempted to examine how various grid-like layouts in Malaysia can be vulnerable to burglary. Upon examination at the macro and micro scale, the findings of this study have shown that layouts that we planners draw and produce can influence burglary. When variables in a layout were considered independently (as shown in this study). not all factors relate strongly to burglary. Nonetheless, the findings of this study has shown that at the macro scale (area level), global integration (radius $n$ ). relates strongly to burglary rate, and at the micro scale (street level), houses in band 1 (street segments with less than 12 houses) are more vulnerable to burglary. It was also suggested that areas constituting of homogenous type of houses (e.g. terraced only) is sifer than areas with heterogeneous type of houses (mix housing type). These findings seem to saggest that planners when drawing up residential layouts must reconsider the hierarchy and connectivity of streets. Although accessibility is essential for the convenience of its residents, too many (or a very permeable layout) will have negative impact on its safety. Similarly, having fewer houses along a street segment may also put houses at risk of being burgled.

This research has attempted to examine the relationship between burglary, urban spaces in grid-like layout and the loeal conditions of layouts in Malaysia. Although, this paper presents partial results of the study, suffice to say examining burglary at the macro and micro scales have provided a glimpse into how spaces interact with burglary. By using space syntax as a tool, it has allowed the comparison of spaces and burglary rate, which otherwise seem impossible. No doubt there are several crime studies that have been conducted in this country, very few have actually attempted to examine at the finer scale. In conclusion, it can be implied that the results of this study have to a certain extent agree with the findings of the study carried out by Hillier and Shu. 


\section{REFERENCES}

Beayon, D. J, K., P. L. Bruntingham, et al. (1994). The influence of strect networks on the patteming of property offenses. Crime Prevention Studies 2: 115-148.

Bowers, K.J, Johnson, S.D, and Pease K. (2005). Victimisation and revictimisation risk, housing type and area: a study of interactions. Crime prevention and community safety: An international journal. 7 (1), pp 7 17.

Brantigham, P. L. B., P.J (1975). Residential burglary and urban form. Urban Studies (12): 273-284.

Hillier, B. (2008). Space and spatiality: what the built environment needs from social theory. Building Research \& Informolion 36(3): 216-230.

Hillier, B, and Sahbaz, O. (2007). Beyond hot spots; using space syntax to understand dispersed patterns of crime risk in the built environment. http//eprints.ucl.ac.uk/18549/. Retrieved 30/08/11

Hillier, B. and Sahbaz, O. (2008). An evidence besed approach to crime and urban design; $O r$, can we have vitality, sustainability and security all at once?

http:/www.spacesyntax.com/Files/MediaFiles/Hillier\%20Sahbaz_An\%2 Oevidence\%20based\%20approach 010408.pdf. Retrieved 01/10

Hillier. B and Shu, S. (2000). Crime and urban layout: the need for evidence. Secure foundations, London: IPPR

Hillier, B. and Stonor, T. (2010). Space Syntax - Strategic Urban Design City Planning Review. The City Planning Institute of Japan. 59/3 (285): 7-11.

Jacobs, J. (1961). The death and life of great American cities. New York: Vintage Books.

Johnson, S. D, and K. J. Bowers (2010), Permeability and burglary risk: are culde-sacs safer?. Quantitathe Criminology 26;89-111.

Newman, O. (1972). Defensible Space: Crime Prevention through Urban Design. New York, MacMillan. 


\section{Appendix 1}

Axial map of the study area in relation to the whole system

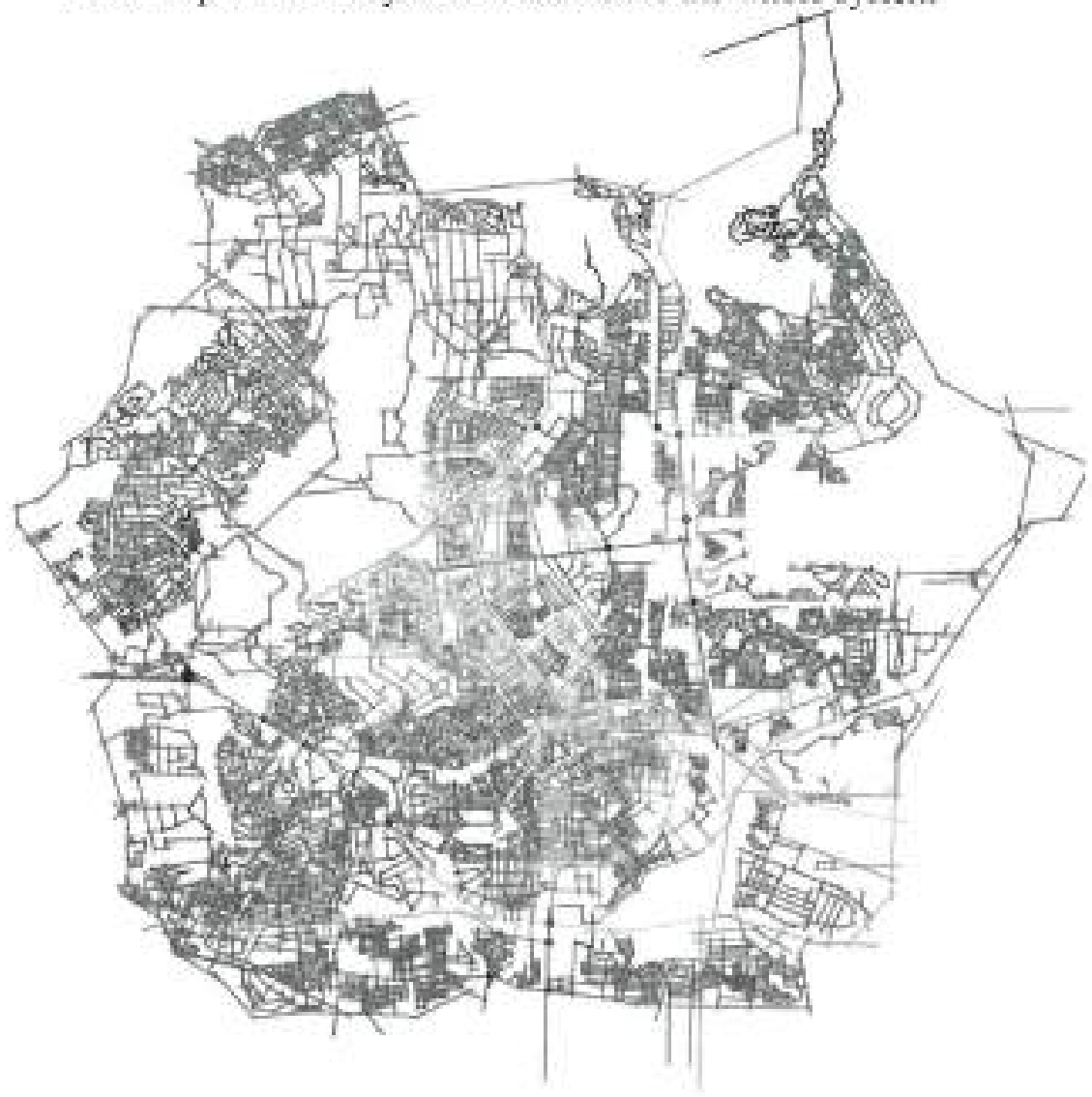




\section{Appendix 2}

Axial maps of case study areas with burglary mapped as white dots
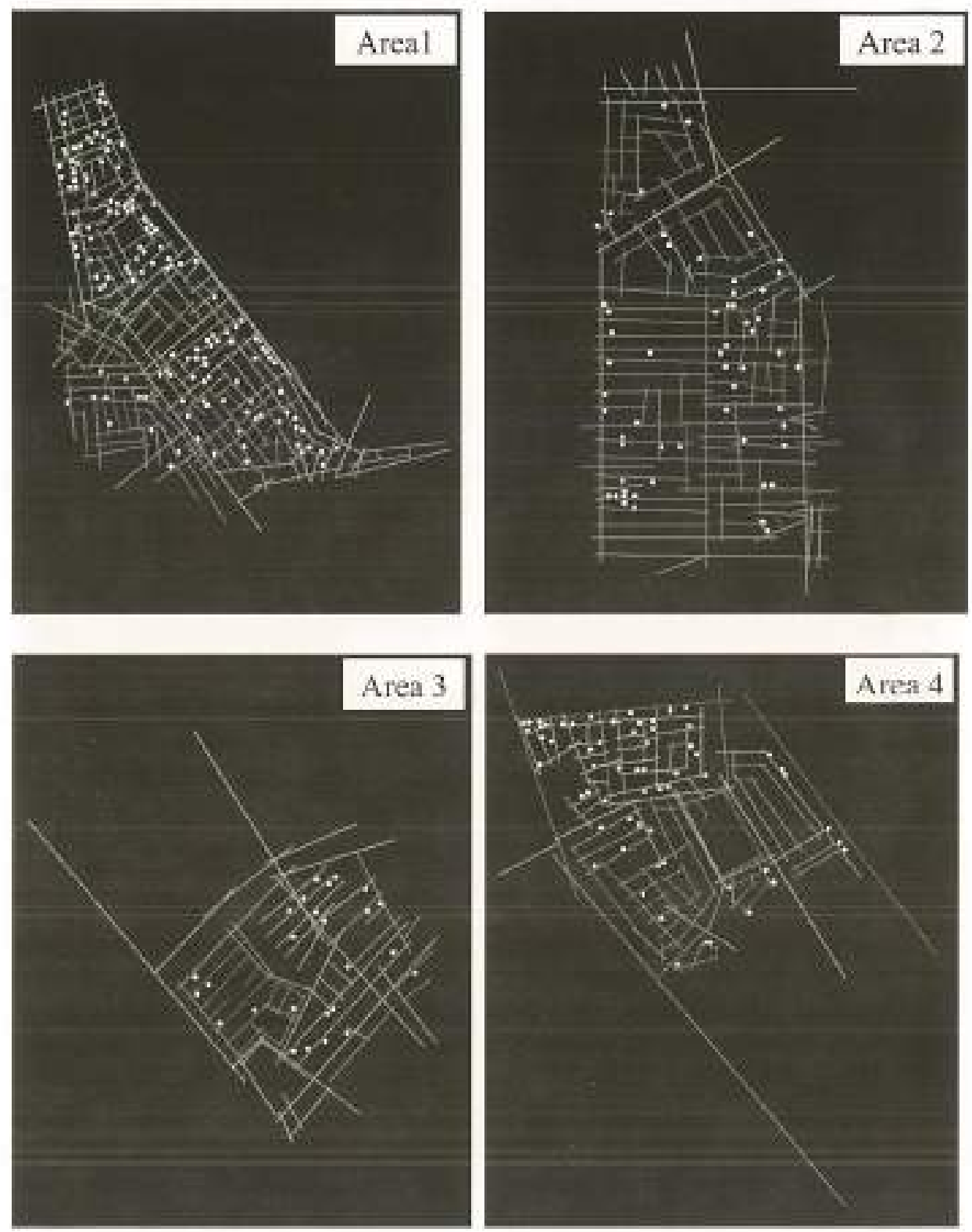

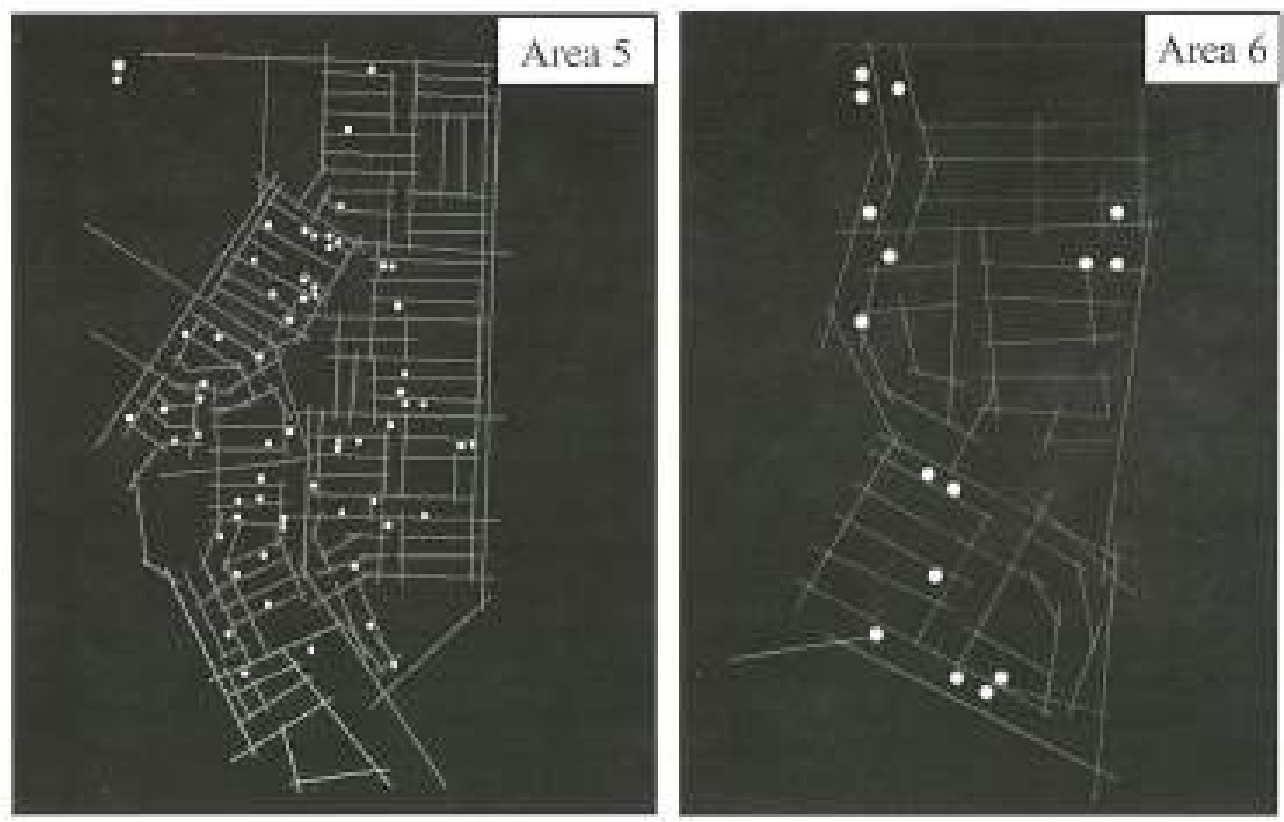